\title{
The Use of Posters in Disseminating HIVIAIDS Awareness Information within Higher Education Institutions
}

\author{
Jenni Gobind \\ Wilfred I. Ukpere \\ Department of Industrial Psychology and people Management, Faculty of Management, \\ University of Johannesburg, South Africa \\ Email: wiukpere@uj.ac.za
}

\section{Doi:10.5901/mjss.2014.v5n20p739}

\begin{abstract}
HIVIAIDS continues to destroy individuals and communities within Africa. The need to explore creative forms of awareness information dissemination remains necessary. Posters continue to present a cheap alternative to expensive mass media campaigns. However, the effectiveness of posters in disseminating HIV/AIDS awareness information is difficult to ascertain. Designers of posters aim for visual appeal, with the intention that the posters attract the attention of target audience. Studies on how often posters are being noticed at universities, has not been undertaken. Studies have been undertaken to determine the use of posters within waiting rooms and emergency centres however, these environments allow for time to peruse unlike university corridors. This paper examines the visibility of posters at a university in order to determine the effectiveness of the use of posters in disseminating HIVIAIDS awareness information.
\end{abstract}

Keywords: Awareness, Dissemination, Information, Posters, Small media

\section{Introduction}

The question on some people's minds is whether the Human Immunodeficiency Virus/Acquired Immunodeficiency Syndrome (HIVIAIDS) can be compared to the Black Death of the middle ages? The bubonic plague destroyed a third of Europe's population in six years. Over a century, the bubonic plague killed 40 million people as it spread across the globe (DeNoon, 2013). When compared to HIVIAIDS, the global trend of current pandemic is disquieting. Since the beginning of the HIVIAIDS epidemic, "almost 70 million people have been infected with the HIV virus and about 35 million people have died of AIDS. Globally, 34.0 million [31.4-35.9 million] people were living with HIV at the end of 2011. An estimated 0.8\% of adults aged 15-49 years worldwide are living with HIV, although the burden of the epidemic continues to vary considerably between countries and regions. Sub-Saharan Africa remains most severely affected, with nearly 1 in every 20 adults (4.9\%) living with HIV and accounted for $69 \%$ of the people living with HIV worldwide" (Global Health Observatory, 2013). HIVIAIDS has created the most significant global public health crisis in modern history. Despite the complexity and scale of the epidemic, there is still a lack of worldwide strategies to impart AIDS education.

In South Africa, for instance, two out of three pupils in grade 6 do not have the minimum knowledge about HIVIAIDS, which is necessary for them to protect their health (John, 2012). The crisis also lies with younger pupils at primary and high schools. According to Thaver (2012), "while current sexual and HIV and AIDS education in South African secondary schools is problematic, it does have the potential to be one of the most important and effective mechanism for combating the HIV and AIDS epidemic". AIDS education in many countries is still undertaken, to a great extent, by government agencies and grassroots organisations led by community activists, who are often motivated local citizens. In South Africa, organisations such as Higher Educations HIVIAIDS programme (HEAIDS) have attempted to educate students on the impact and consequence of HIVIAIDS.

Since the first occurrence of HIVIAIDS, the responsibility of educating the world's public has gained dramatically in significance. In many countries, the poster as a medium of information was unknown before the emergence and identification of the HIV virus. With a disease linking sexuality and sexual behaviour deeply rooted in culture and tradition, messages to raise awareness and encourage preventive behaviour have varied depending on the nature or profile of the audience. "The poster has played a special role in promoting AIDS awareness and safe sex education across cultures, different aims, messages, visual metaphors and strategies have strongly influenced the content and design of AIDS posters" (Resnick, 2010). These messages can successfully reach specific targeted groups because the poster as a 
medium is cheap and easy to produce.

Regardless of cultural differences, AIDS posters are meaningful to viewers because they frequently draw on images from popular culture and express the living habits of people, which can vary in approach and style. Consequently, the messages in posters can illuminate how public health educators and activists see themselves and their audiences, and how they conceptualize the disease and define 'normal' behaviour within each given culture or context. The approach in which HIVIAIDS posters are designed in disseminating HIVIAIDS information is often generalised, detached from discrimination and stigma. Posters seem to be inviting, non-intrusive and effective.

\section{Problem Statement}

HIVIAIDS continues to pose a health risk within education institutions. In light of the consistent increase in HIVIAIDS prevalence, the need for alternative ways of creating HIVIAIDS awareness needs to be explored. Higher Education Institutions are positioned to take advantage of their access to young minds and effectively disseminate HIVIAIDS information whenever possible. With the barrage of social media, the hope for possible means and ways of disseminating HIVIAIDS information amongst youth can be challenging. Youth choose to engage in social media rather than being engaged with their surroundings that form their community. Resorting to alternative and the so called 'in your face' campaigns is essential. Apart from social media being a vehicle for the dissemination of HIVIAIDS awareness information, posters although traditional, are useful when used in high foot traffic environments like university corridors and student cafeterias.

\subsection{Research Question}

The statement above led to the following research questions:

- What does a small media especially posters comprise of?

- How does a poster communicate HIVIAIDS awareness information?

- Are posters effective in disseminating HIVIAIDS awareness information?

\subsection{Research objectives}

The objectives of the paper are:

- To unpack what a poster as an example of small media comprises of,

- To investigate how posters communicates HIVIAIDS awareness information, and

- To evaluate the effectiveness of posters in disseminating HIVIAIDS awareness information.

\subsection{Significance of the study}

The results of this study could prompt Higher Education Institutions and other organisations to reconsider the use of posters as a means of disseminating HIVIAIDS awareness information. Posters are an affordable and accessible form of communication. The creative manner in which posters are presented, allows for consistent renewal of HIVIAIDS awareness messages. This renewal is vital in maintaining interest in the subject matter, especially in a society that claims to have an overload of HIVIAIDS awareness campaign.

\section{Theoretical Framework}

A poster is an example of small media which is often a large print or notice used for advertisements or decoration. Posters are often regarded as the easiest and cost effective way to communicate message to a large mass audience. Posters have been a powerful force in shaping public opinion and spreading propaganda. One of the many objectives of posters, as with other form of communications media is to influence attitudes, market a product or change behaviour patterns. Public health posters are clearly in the third category, their purpose being to alter the consciousness of the public to bring about an improvement in health practices (Nunyenge, 2013). Posters aim at presenting information in a succinct and condensed manner. However, posters are not interactive and often lacks in-depth and as such not given the necessary attention it deserved. Posters according to Rowe (2009), if accompanied by a short presentation, can help with aural and verbal learning exchanges. 
The small media or posters can play a critical role in creating an enabling and supportive environment where some of the taboo issues and underlying driving forces of HIVIAIDS can be addressed. The small media is in the position to create greater public awareness of HIVIAIDS, which is necessary before individuals critically look at the challenges posed by the epidemic, in order to be able to make informed decisions to help prevent infections, protect themselves, and ensure proper care and treatment of people living with HIV (John, 2012). News coverage reinforces information that people receive about the epidemic from other sources, such as their friends, health care workers and billboards. Small media is often underestimated, however "the benefits that such small media have over large media include their being more strongly rooted in African cultures and having longer periods of effectiveness" (Beaudion,2007:199).

\subsection{Small media}

Small media are written and printed resources usually intended to be taken away or distributed to members of a target audience. They include text-based interventions such as pamphlets, flyers, newsletters, booklets, posters or cards. They come in a variety of shapes and sizes with variable amounts of text. They are usually made available, or actively distributed in social or service settings. Alternatively, newsletters or magazines are sometimes mailed (or emailed) directly to users on a mailing list. There is some overlap between small media and mass media, which becomes apparent when considering how the setting can change the name of the intervention. For example, health promotion information displayed in a shop may be called a 'poster' and considered small media, but a similar poster in a larger format (example a billboard) from the same campaign is called mass media.

Leaflets and other small media fulfil a larger purpose to ensure that a comprehensive source of information on a specific topic was achieved. For instance, as a part of an HIV prevention campaign, different types of small media have the ability to draw service users from initial interest or campaigns, to picking up a leaflet. This enables them to gain more detailed information, to making a decision to seek further interventions, or perhaps to alter their behaviour. Written interventions cannot be expected to meet complex social needs or address interpersonal problems. Instead, they are best used to convey information, and to raise awareness. In addition, small media can offer information about organisations and their services, thereby promoting access to other interventions.

According to Nunyenge, (2013) there are various categories or type of posters. Advertising posters are most common as they generally advertise or promote products. These types of posters are very attractive and colourful. This type of poster is accompanied by intense competition in the design. It is anticipated that eye-catching posters, can attract more customers. The second type of poster, the propaganda posters, is often used during political campaigns or corporate environments to portray a company's corporate philosophy. These kinds of posters can also be termed corporate communications posters (Nunyenge, 2013). The third type of poster, namely the informative posters are used to spread awareness and information, example HIVIAIDS awareness posters. The fourth type of poster, namely the subject poster, usually has a certain specific subject example prints or movie posters. The fifth type of poster, namely the affirmation posters convey motivational or inspirational messages. The sixth type of poster, namely the educational posters is used in academia to promote and explain research work. They are typically shown during conferences, either as a complement to a talk or scientific paper, or as a publication (Nunyenge, 2013). Lastly, the health posters often found in health practitioners' rooms often communicate preventive health care.

\subsection{Posters as a tool for communication}

Posters are effective tools in raising awareness. Posters are the primary non-electronic communication piece utilised to reinforce messages in a communication plan (International labour Organisation (ILO), 2010). When strategically placed, posters spark interest in order to get individuals curious and involved in a program. Posters are typically displayed in areas with high user traffic like corridors, common rooms, meeting rooms and offices. Posters are unlike billboards which are huge and attract attention by their sheer size. Posters are designed to be attached on the walls and designed to communicate a message. They need to be attractive, eye-catching and informative. Posters are used for several purposes. They could be used by advertisers to promote an event or a film. They could also be used by non-profit organizations to create social awareness (Nishtar, et al., 2004).

In order for posters to be used as an effective communication tool, there is a need for it to be visually striking. Posters are designed to attract the attention of the passer-by with the intention of enticing a second look at what the poster has to say. "Posters are widely used for health promotion because they constitute an inexpensive way of providing written information to a large proportion of the population. This educational approach can be used to encourage people to implement preventive measures, undergo screening or adopt good treatment practices. Despite the limitations of posters 
as a means of health education, previous studies have reported that poster displays in hospital waiting rooms and emergency departments are an effective vehicle for health education on several topics (such as antismoking campaigns, family planning, AIDS prevention and promotion of physical activity)" (Gignon, 2012:1).

\section{Posters as a Tool for Disseminating HIVIAIDS Awareness Information}

Different aims, messages and strategies have strongly influenced the content and design of HIVIAIDS posters that address specific target groups. Many early HIVAIDS prevention messages, for example, were aimed particularly at the homosexual male community and intravenous drug users of all races (Resnick, 2010). While some created an atmosphere for open discussion or invite more participation from observers, others attempted to condemn or instil fear. Owing to the fact that people understand pictures in different ways, depending on environment, experience, education, beliefs and sexual behaviour, which is deeply rooted in culture and tradition, messages to raise awareness and encourage preventive behaviour varies depending on the intended audience (Kerr, et al., 2000).

Regardless of differences, posters are meaningful to viewers because they frequently draw on images from popular culture and express the living habits of people. As such, the messages in posters reveal how public health educators and activists see themselves and their audiences, and how they conceptualise disease and define normal behaviour (Hossain et. al., 2003). Recognising the fact that traditional health education methods are frequently ineffective, the creators of posters often use the combination of visual and textual messages to normalise safe sex and consequently create awareness. Although posters can increase awareness of health promotion issues, their messages are not necessarily effective in changing patients' behaviour and lifestyles (Ward, 1994; Gignon, 2012). The intention would then be to continue to create awareness until society recognises a shift in behaviour and lifestyle change. Therefore the need to persist with awareness campaign is imperative.

\section{Research Methodology and Design}

The researchers used a mixed method approach. Practical considerations suggested a survey-based field study design, which is combined with semi-structured interviews. The mixed method research studied the effectiveness of posters in creating HIVIAIDS awareness within a Higher Education by using a self-administered survey questionnaire and semistructured interviews. This entailed the development and administration of a survey questionnaire that explored academic, administrative staff and student perceptions of HIVIAIDS posters within the university. This was followed by one-on-one interviews that supported the data gathered from the quantitative phase of the study. In terms of the research instrument, the researchers developed a standardised instrument for the field study. Questionnaires were sent to a total of 739 academics, administrative staff and students. Semi structured interviews were also used to obtain further information from participants, with the intention of preventing misunderstandings or misinterpretations of the questionnaires as the researchers can explain exactly what information they need from the respondents and can immediately clarify uncertainties about the questions. The research questions were explored in the context of the problem statement and aims by means of descriptive statistics. In particular, frequencies were used to explore relationships and differences amongst the categorical variables. The total values were computed to give a percentage of responses. These provide a clearer picture of the responses for those who noticed the posters and those who did not. It is also pertinent to mention that the first phase (quantitative phase) of the exploratory sequential design was followed by the qualitative phase. As aforementioned, this second phase of the data analysis was conducted using semi-structured interviews. It is also important to mention that the researchers relied on a combination of convenience and purposeful sampling. Sample groups where purposefully identified, and in some instances conveniently sampled. Adherence to accepted ethical standards was observed, and participants were informed as to confidentiality, anonymity and the purpose of the research.

\section{Data Analysis}

\subsection{Description of the Sample}

Information for the empirical study was obtained from academic, administrative staff and students from within a South African university. From the total of 970 questionnaires distributed to academic, administrative staff and students, 739 responses were received which showed a relatively good response rate of $76.2 \%$. Demographic data was collected to establish according to the category of the various stakeholders (academic, administrative staff and student). This was gathered in order to quantify the responses of the academic, administrative staff and students. 130 (17.5\%) academics, 
$116(15.7 \%)$ administrative staff and $493(66.8 \%)$ students participated in the study. There were predominately female respondents $(62.9 \%)$ compared to male (37.1\%).

\subsubsection{Overall response to visibility of posters at the university}

Participants' overall response to the visibility of the posters at the university was investigated in order to determine whether the university population noticed the HIVIAIDS posters within and around the university. As Ward (1994) and Gignon (2012:6) have suggested, posters have the ability to increase awareness of health promotion issues. Therefore, the higher the number of participants indicating that they have noticed the posters, would indicate that some level of awareness of the poster and more importantly the content has been far reaching to the university population.

Table 1: Are HIVIAIDS posters visible at the University?

\begin{tabular}{clcccc} 
& & Frequency & Percent & Valid Percent & Cumulative Percent \\
\hline \multirow{3}{*}{ Valid } & No / Don't know & 204 & 27.6 & 28.1 & 28.1 \\
& Yes & 523 & 70.8 & 71.9 & 100.0 \\
& Total & 727 & 98.4 & 100.0 & \\
\hline \multirow{2}{*}{ Missing } & System & 12 & 1.6 & & \\
\hline & Total & 739 & 100.0 & &
\end{tabular}

Of a total of 739 participants 12 participants did not respond to the question. Participants that did respond 204 (27.6\%) indicated that the posters were not visible compared to $523(70.8 \%)$ that indicated that the posters were visible.

\section{Academic Response to the Visibility of HIVIAIDS Posters at the University}

The rationale for this information was to determine whether academics were as responsive to HIVIAIDS posters as compared to administrative staff and students.

Table 1: Academic response to the visibility of HIVIAIDS posters at the University

\begin{tabular}{llcccc} 
& & Frequency & Percent & Valid Percent & Cumulative Percent \\
\hline \multirow{3}{*}{ Valid } & No/ Don't know & 39 & 30.0 & 30.7 & 30.7 \\
& Yes & 88 & 67.7 & 69.3 & 100.0 \\
\multirow{2}{*}{ Missing } & Total & 127 & 97.7 & 100.0 & \\
& System & 3 & 2.3 & & \\
& Total & 130 & 100.0 & & \\
\hline
\end{tabular}

$(\mathrm{n}=130)$

The above table revealed that of 130 academics, $3(2.3 \%)$ of academics did not respond to the question. However, 88 $(97.7 \%)$ of those who responded, indicated that poster were visible, while $39(30 \%)$ indicated that posters were not visible.

\subsubsection{Administrative staff response to the visibility of HIVIAIDS posters at the University}

The rationale for including this group of participants was to determine whether administrative staffs were as responsive to HIVIAIDS posters at the university, in order to compare their response with other stakeholders, namely academics and students.

Table 3: Administrative staff response to the visibility of HIVIAIDS posters at the University

\begin{tabular}{llcccc}
\hline & & Frequency & Percent & Valid Percent & Cumulative Percent \\
\hline \multirow{3}{*}{ Valid } & No / Don't know & 27 & 23.3 & 23.7 & 23.7 \\
& Yes & 87 & 75.0 & 76.3 & 100.0 \\
\multirow{2}{*}{ Missing } & Total & 114 & 98.3 & 100.0 & \\
& System & 2 & 1.7 & & \\
& Total & 116 & 100.0 & & \\
\hline
\end{tabular}

$(n=116)$ 
According to table 7 administrative staff response to the visibility of HIVIAIDS posters at the University, revealed that a total of 114 administrative staff responded to this question, however, 2 (1.7\%) did not answer. Of the 114 that responded, 87 (75\%) indicated that posters were visible, while 27 (23\%) indicated that posters were not visible.

\subsubsection{Students' response to the visibility of HIVIAIDS posters at the University}

The reasoning behind this section is to determine how the largest target group within the university are responsive HIVIAIDS posters in the university as a medium awareness, as compared to other stakeholders, namely academics and administrative staff.

Table 4: Students' response to the visibility of HIVIAIDS posters at the University

\begin{tabular}{llcccc}
\hline & & Frequency & Percent & Valid Percent & Cumulative Percent \\
\hline \multirow{3}{*}{ Valid } & No / Don't know & 138 & 28.0 & 28.4 & 28.4 \\
& Yes & 348 & 70.6 & 71.6 & 100.0 \\
& Total & 486 & 98.6 & 100.0 & \\
& System & 7 & 1.4 & & \\
& Total & 493 & 100.0 & & \\
\hline
\end{tabular}

$(n=493)$

According to table 10 above a total of $486(98.6 \%)$ of students responded to this question, while $7(4.1 \%)$ did not respond to the question. Of the 484 that responded, $348(70.6 \%)$ indicated that posters were visible and $138(28 \%)$ indicated that posters were not visible.

\subsection{Semi-structured interviews: participants' responses}

During the semi-structured interviews participants were asked if programme co-ordinators created HIVIAIDS awareness. Administrative staff when asked about the various ways in which HIVIAIDS programme co-ordinators created programme awareness they agreed that co-ordinators created awareness with the aid of notice boards, posters, circulars and testing. An administrative staff when interviewed stated "mostly the posters but, in my opinion they are not effective they stay up for an hour most until a new one comes up". Another added that posters generally focused on awareness: "from posters it is about awareness normally". When academics and students were asked the same question, they responded differently. The first academic said that condoms created some form of awareness: "not really except for the condoms, we are a small campus no, sometimes at the gates this has no impact". The second added that posters created awareness "I have seen posters, notice boards, flyers and circulars". The last academic stated that she knew her status and did not bother "I know my status so I don't bother" (Ac2). Two students that were interviewed mentioned that the use of posters was effective. The third said it varied and the fourth, said to an extent: "It is everywhere notice boards posters it is effective for me". "It is effective if they are doing testing helps them change if they have a scare". "It varies if you make it your own it would appear effective if not then no". "To a certain extent it is effective some actually give themselves time to find out seems effective to other people".

\section{Discussion of Findings}

\subsection{Responsiveness of stakeholders to posters as HIVIAIDS awareness information dissemination}

Posters have the ability to present information through art and text. Often categorised as small media the impact that posters generate cannot be mistaken. Literature has afforded examples of studies were poster have proven effective in disseminating information. This study was conducted within four university campuses amongst 739 participants who belonged to three different strata that encompass the university population. Of the total number of participants $70.8 \%$ of the participants have indicated that HIVIAIDS posters at the university were visible. Suggesting that, participants firstly, read the poster in order to determine the nature of poster. Secondly, in so doing recollected that they had seen the specific poster at the university. Administrative staff appeared to have taken greater notice of the posters at the university. This could be attributed to the nature of the jobs that allow for far more movement around the university unlike academic staff who tend to maintain set patterns of movement. Students tend to follow similar patterns of movement as academics 
which are generally determined by their lecture sessions and placement of lecture venues. The above is also supported by the findings of Ntombela, Stilwell and Leach (2013:79) which states that "most university academics prioritise academic matters over anything else, very few students regarded this source as notable". Ntombela et al (2013) concluded that academics were criticised for not highlighting HIVIAIDS issues sufficiently and for concentrating rather on academic issues by $39 \%$ or $14.3 \%$ of the respondents. The findings of Ntombela et al (2013) revealed that with the exception of the Social Sciences where HIVIAIDS issues were touched on, $35 \%$ or $12 \%$ of the students found academics to be too overburdened with the need to meet curriculum requirements than to devote extra time for anything else. The need to describe the differences in academic responses may assist programme co-ordinators and media campaigners with valuable data when profiling a target audience like the overburden academics described above. Lower response in certain groups may suggest the implementation of a group specific poster using a different medium.

Nevertheless, in spite of the high notice rate of posters by administrative staff, literature seems to suggest that HIVIAIDS prevalence rate among university administrative staff is considered to be relatively high. A 2010, study revealed that HIV prevalence among academic staff was 1.5\%, administrative staff $4.4 \%$ and service staff $12.2 \%$ (HEAIDS, 2010). The need to quantify administrative staff awareness of posters is necessary. In line with literature, media example posters are seems to be valuable source of awareness information. A poor response may suggest that programme coordinators may rely on posters as a means of improving HIVIAIDS awareness levels among this group of stakeholders.

With regards to the student group, Oppong Asante and Oti-Boadi (2013:274) concur that university students in Ghana seem to rely on both print and electronic media as the major source of HIVIAIDS information and therefore, this form of media has an important role to play in raising AIDS awareness among young adults including university students. Print media according to Abdool Karim, Meyer-Weitz and Harrison (2009) have also been "proven to be effective in increasing knowledge, improving self-efficacy to use condoms, influencing social norms, increasing the amount of interpersonal communication and raising awareness of health services". The need to target this particular group has been intensely deliberated.

\subsection{Effectiveness of Posters in disseminating HIV/AIDS awareness Information}

The study has made an inroad into ascertaining whether posters are effective in disseminating HIVIAIDS awareness information. The results of the data suggest that participants have noticed posters that have been placed in and around the university. A similar type of study was conducted in Pakistan. The objective of the study was to investigate the effectiveness of posters as a tool, for imparting information related to high blood pressure (Nishtar, 2004). The researchers of this study concluded that more than half the people understood the overall message of the poster. However, it was difficult to assess the effectiveness of the poster in changing people's behaviour regarding blood pressure check-ups. A study conducted in 2003 noted that posters with pictures on the health effects of arsenic poisoning were found to be very effective in attracting people. Hossain (2003) noted that posters "can play a vital role in creating consciousness among people of different strata. If chosen carefully, the pictures of symptoms will not frighten target audiences". Posters showing the symptoms of arsenicosis helped community health workers identify patients. The study noted that print media conveys information quickly, reaches many people and encourages them to take action. The advantages of using printed materials are the ease of use, portability, low cost, and the power of colour and graphics to portray concepts (Hossain, 2003). A 2013 study undertaken by Nunyenge (2013) concluded that although about 76\% of respondents saw HIV poster regularly, however, only a few of them had some form of idea as to what the poster entailed. Posters were visible yet the effectiveness or the meaning people derived from HIV posters was not determined. Nishtar (2004), Hossain (2003) and Nunyenge (2013) concluded that participants have noticed posters and yet their knowledge of the content of posters was not assessed. However, a study conducted by Gignon (2012), Ward (1994) and Kerr (2000) established that despite the "limitations of posters as a means of health education, previous studies have reported that poster displays in hospitals, waiting rooms and emergency departments are an effective vehicle for health education on several topics such as antismoking campaigns, family planning, AIDS prevention and promotion of physical activity". Unlike hospitals, waiting rooms and emergency departments, university corridors are high traffic areas that seldom permit the time often spent at a waiting room. Sheer boredom or restlessness compels patients or companions to read and reread posters in a waiting room. Hence, the time spent reading posters would inadvertently determine the level of content awareness.

\section{Limitations and Scope for Future Research}

The limitation of this study remain that the level of content awareness was not assessed. However, considering the time 
constraints placed on most of the target audience, this would have better suited a quantitative study. This limitation allows for future research were the level of the poster content can be assessed to determine true effectiveness of the impact of the poster. The data derived from the study would benefit programme co-ordinators when planning and designing HIVIAIDS campaigns and awareness drives.

\section{Conclusion}

In conclusion, this paper has provided insight into the value placed on posters for disseminating HIVIAIDS awareness information at the target university. The data gathered suggests that participants have noticed HIVIAIDS posters at the university thus, offering programme co-ordinators reassurance of the incremental efforts made towards HIVIAIDS awareness within the university. However, the extent of the awareness is yet to be determined. Nevertheless, the benefits of repetitive information dissemination cannot be disregarded. Programme co-ordinators may rely on the study in reevaluating the positioning of posters for future reference, whilst considering the needs and habits of the target audience.

\section{Acknowledgements}

This paper acknowledges the funding and assistance of the National Research Fund (NRF) of South Africa.

\section{References}

Abdool Karim Q, Meyer-Weitz, \&., Harrison A. (2009) Interventions with youth in high prevalence areas. In Mayer KH, Pizer HF, editors. HIV preventions: A comprehensive approach. London: Academic Press

Beaudoin, C. E (2007). HIV prevention in sub-Saharan Africa: a multilevel analysis of message frames and their social determinants Health Promotion International, Vol. 22 No. 3 [online] http://heapro.oxfordjournals.org/content/22/3/198.full.pdf (Accessed 23 July 2013)

DeNoon, D.J (2013). AIDS worse than Black Death, WebMD Health News [online] available http://www.webmd.com/hivaids/news/20020125/aids-worse-than-black-death (Accessed 23 July 2013)

Higher Education HIV and AIDS Programme (HEAIDS) (2010) HIV prevalence and Related factors - Higher Education Sector Study, South Africa, 2008-2009. Pretoria: Higher Education South Africa

Global Health Observatory (GHO) World Health Organisation (WHO) (2013). HIVIAIDS [online] available http://www.who.int/gho/hiv/en/ (Accessed 24 July 2013)

Gignon, M., Idris, H., Manaouil, C, \&., Ganry,O (2012). The waiting room: vector for health education? the general practitioner's point of view Biomed Central [online] available http://www.biomedcentral.com/content/pdf/1756-0500-5-511.pdf (accessed 23 July 2013)

Hossain, Z ., Quaiyum Md., \&. Jakariya, Md (2003). Using IEC Materials for Mass Communication: Experiences of an Arsenic Mitigation Project in Bangladesh. Bangladesh Journal of Communication [online] available http://research.brac.net/publications/using iec_for_mass_communications_pdf.pdf (Accessed 3 August 2013)

International labour Organisation, (ILO) (2010). Learn about it at work: an HIV poster campaign in Russia [online] available http://www.ilo.org/global/about-the-ilo/newsroom/features/WCMS 141842/lang--en/index.htm (Accessed 23 July 2013)

John, V (2012). ' Alarm' at SA pupils' lack of HIVIAids knowledge, Mail and Guardian [online] available http://mg.co.za/article/2012-0209-sa-pupils-lack-of-hivaids-knowledge-alarming (Accessed 24 July 2013)

Kerr, J., Eves, F.\&., Carroll, D (2000). Posters can prompt less active people to use the stairs. Journal of Epidemiology Community Health 2000, 54:942-943. [online] available http://jech.bmj.com/content/54/12/942.full (Accessed 3 August 2013)

Nishtar,S., Zoka, N., Nishtar, S.S., Khan, S.Y., Jehan,S., \&., Mirza, Y.A (2004). Posters as a Tool for disseminating Health related Information in a Developing Country: a pilot experience. Journal of Pakistan Medical association [online] available http://jpma.org.pk/full article text.php?article id=482 (Accessed 3 August 2013)

Ntombela, M., Stilwell, C., \& Leach, A. (2013). Hello tomorrow? Sources of HIV / Aids information used by residential students at the University of Natal. South African Journal Of Libraries And Information Science, 74(1). [online] available doi: http://dx.doi.org/10.7553/74-1-1259 (Accessed 1 July 2014)

Nunyenge, R (2013). The Meaning People Make of HIV Posters: a Case Study on Health Improvement at Jirapa District in the Upper West Region of Ghana. Journal of Biology, Agriculture and Healthcare [online] available http://www.iiste.org/Journals/index.php /JBAH/article/view/6260/6389 (Accessed 3 August 2013)

Oppong Asante,K \&., Oti-Boadi, M (2013) HIVIAIDS knowledge among undergraduate university students: implications for health education programs in Ghana African Health Sciences Vol 13 Issue 2 June 2013 [online] available http://www.ncbi.nlm.nih.gov/pmc/articles/PMC3824504/pdf/AFHS1302-0270.pdf (Accessed 1 July 2014)

Resnick, E (2010). Graphic intervention 25 Years of International AIDS Awareness Posters 1985-2010 [online] available http://www.posterpage.ch/exhib/ex262aid/ex262aid.htm (Accessed 24 July 2013)

Rowe, N \&., Illic, D (2009). What impact do posters have on academic knowledge transfer? A pilot survey on author attitude and experienced. Biomedcentral Medical Education [online] available http://creativecommons.org/licenses/by/2.0 (Accessed 3 August 
2013

Thaver, L (2012). Sexual and HIVIAIDS Education in South African Secondary Schools, Open Society Initiative of Southern Africa, [online] available http://www.osisa.org/buwa/south-africa/sexual-and-hivaids-education-south-african-secondary-schools (Accessed 24 July 2013)

Ward, K \&., Hawthorne, K (1994). Do patients read health promotion posters in the waiting room? A study in one general practice. British Journal of General Practice [online] available http://www.ncbi.nlm.nih.gov/pmc/articles/PMC1239083/pdf/brjgenprac000250047.pdf (Accessed 23 July 2013)

World Health Organisation (WHO). (2011). Global HIVIAIDS response: epidemic update and health sector progress towards universal access: progress report 2011. [online] available http://whqlibdoc.who.int/publications/2011/9789241502986_eng.pdf (Accessed 23 July 2013) 